
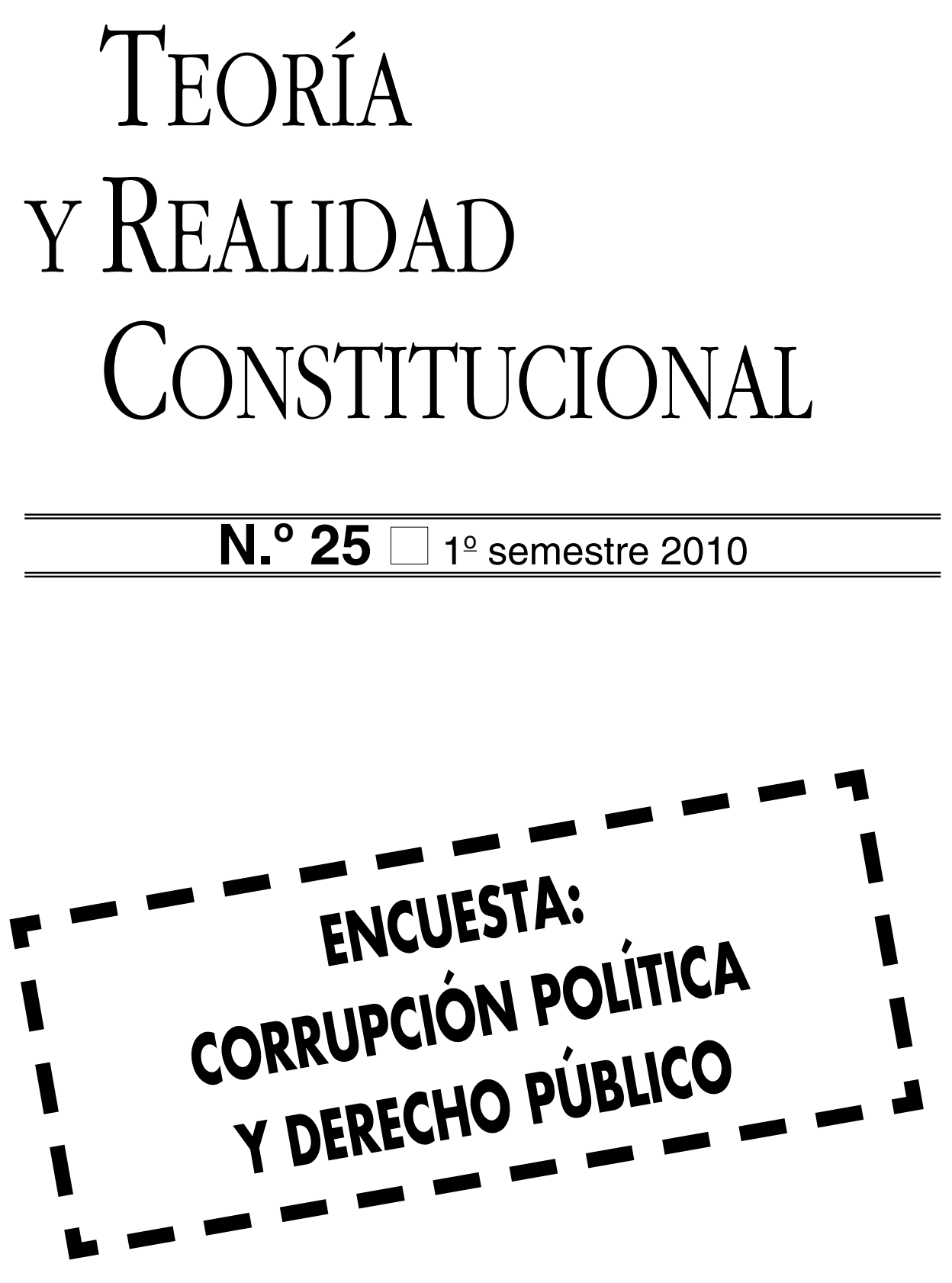


\title{
COMENTARIO AL DICTAMEN DEL CONSEJO DE ESTADO RELATIVO AL ANTEPROYECTO DE LA LEY GENERAL DE LA COMUNICACIÓN AUDIOVISUAL
}

\author{
ISABEL SERRANO MAÍlLO \\ Profesora de Derecho Constitucional \\ Universidad Complutense de Madrid
}

\author{
SUMARIO \\ I. Cuestiones previas. \\ II. Objetivos. \\ III. Novedades. \\ IV. Observaciones. \\ V. Valoración general.
}

\section{CUESTIONES PREVIAS}

\section{I.1. UN DICTAMEN DE CARÁCTER PRECEPTIVO}

Según establece la Constitución Española, «el Consejo de Estado ${ }^{1}$ es el supremo órgano consultivo del Gobierno" ${ }^{2}$ y puede ser oído siempre que el Presidente o uno de los Ministros lo considere oportuno. Como norma general, la consulta no es obligatoria ni los dictámenes vinculantes ${ }^{3}$, pero hay ciertos asuntos en los que la consulta es preceptiva. Los casos de consulta obligada son: "1) Anteproyectos de reforma constitucional, cuando la propuesta no

1 Sobre el Consejo de Estado véase M. SALVADOR MARTINEZ: "El Consejo de Estado ante la reforma constitucional", Revista Teoría y Realidad Constitucional, núm. 16, págs. 467-478.

2 Artículo 107 CE.

3 Artículo 2.2 de la L.O. 3/1980, de 22 de abril, del Consejo de Estado: "El Consejo de Estado emitirá dictamen sobre cuantos asuntos sometan a su consulta el Gobierno o sus miembros. La consulta al Consejo será preceptiva cuando en ésta o en otras leyes así se establezca, y facultativa en los demás casos. Los dictámenes del Consejo no serán vinculantes, salvo que la ley disponga lo contrario". 
haya sido elaborada por el propio Consejo de Estado. 2) Anteproyectos de leyes que hayan de dictarse en ejecución, cumplimiento o desarrollo de tratados, convenios o acuerdos internacionales y del Derecho comunitario europeo. 3) Proyectos de Decretos Legislativos. 4) Dudas y discrepancias que surjan en la interpretación o cumplimiento de tratados, convenios o acuerdos internacionales en los que España sea parte. 5) Problemas jurídicos que suscite la interpretación o cumplimiento de los actos y resoluciones emanadas de organizaciones internacionales o supranacionales. 6) Reclamaciones que se formalicen como consecuencia del ejercicio de la protección diplomática y las cuestiones de Estado que revistan el carácter de controversia jurídica internacional. 7) Anteproyectos de Ley o proyectos de disposiciones administrativas, cualquiera que fuere su rango y objeto, que afecten a la organización, competencia o funcionamiento del Consejo de Estado. 8) Transacciones judiciales y extrajudiciales sobre los derechos de la Hacienda Pública y sometimiento o arbitraje de las contiendas que se susciten respecto de los mismos. 9) Separación de Consejeros Permanentes. 10) Asuntos de Estado a los que el Gobierno reconozca especial trascendencia o repercusión.11) Todo asunto en que, por precepto expreso de una Ley, haya de consultarse al Consejo de Estado en pleno" ${ }^{4}$.

Así pues y teniendo en cuenta que uno de los objetivos del Anteproyecto es transponer la Directiva 2007/65/CE, de 11 de diciembre, al Derecho interno español, parece claro que estamos ante un caso de obligada consulta al Consejo de Estado, del tipo recogido en el artículo 21. 2 de la Ley del Consejo de Estado. ${ }^{5}$

\section{I.2. Fundamento COnStitucional}

En este punto el Consejo de Estado remite al propio Anteproyecto y, más concretamente, a la disposición final segunda donde se establece: "1. Los Titulo I y II se dictan en virtud de la competencia del Estado prevista en el artículo 149.1.276 para establecer las normas básicas del régimen de prensa, radio y televisión, y, en general, de todos los medios de comunicación social, sin perjuicio de las facultades que en su desarrollo y ejecución correspondan a las Comunidades Autónomas. 2. Los Títulos III y IV se dictan en virtud de la competencia del Estado prevista en el articulo $149.1 .13^{7}$ para establecer las bases y coordinación de la planificación general de la actividad económica. 3.

4 Artículo 21 de la Ley del Consejo de Estado.

5 Véase pág. 21 del Dictamen 1387/2009, de 17 de septiembre.

6 Artículo 149.1.27 CE: «1. El Estado tiene competencia exclusiva sobre las siguientes materias. (...) Normas básicas del régimen de prensa, radio y televisión y, en general, de todos los medios de comunicación social, sin perjuicio de las facultades que en su desarrollo y ejecución correspondan a las Comunidades Autónomas".

7 Artículo 149.1.13 CE: «1. El Estado tiene competencia exclusiva sobre las siguientes materias. (...). Bases y coordinación de la planificación general de la actividad económican. 
El Titulo V se dicta en virtud de la competencia del Estado prevista en el artículo $149.1 .27^{8}$ para regular la comunicación audiovisual de cobertura estatal. 4. El Título VI se dicta en virtud de las competencias del Estado referidas a los apartados anteriores. Sin perjuicio de la competencia de las Comunidades Autónomas para tipificar infracciones adicionales". No obstante, el Consejo de Estado tomando como referencia diversas sentencias del Tribunal Constitucional, considera que debiera tenerse en cuenta también el artículo 149.1.21 $\mathrm{CE}^{9}$, en cuanto que recoge las telecomunicaciones y la radiocomunicación como materias exclusivas del Estado, en relación con el articulo 149.1.27 CE, ya visto. Según el TC, opinión que recoge y comparte el Consejo de Estado: "...los títulos competenciales dispuestos en el artículo 149.1.21 de la Constitución - telecomunicaciones y radiocomunicación como competencia exclusiva del Estado- y en el apartado 27 del mismo precepto - televisión y otros medios de difusión y comunicación social en cuanto competencia compartida entre el Estado y las Comunidades Autónomas- se limitan y contrapesan entre sí impidiendo el mutuo vaciamiento de sus contenidos respectivos y, en este sentido, no pueden desligarse totalmente, aunque no deben llegar a solaparse, configurando res mixtae $^{10}$.

\section{I.3. ¿DEBE TRAMITARSE COMO LEY ORGÁNICA O COMO LEY ORDINARIA?}

Aunque parece claro que la norma debe tomar forma de ley ordinaria, se plantea la duda de si debería formularse como ley orgánica. Tal posibilidad surge porque podría pensarse que la ley, al regular materias relativas a los medios de comunicación, podría estar desarrollando de alguna manera un derecho fundamental del artículo $20 \mathrm{CE}$. Concretamente el derecho a la infor-

8 Vid supra nota 6.

9 Artículo 149.1.21 CE: «1. El Estado tiene competencia exclusiva sobre las siguientes materias. (...). Ferrocarriles y transportes terrestres que transcurran por el territorio de más de una Comunidad Autónoma; régimen general de comunicaciones; tráfico y circulación de vehículos a motor; correos y telecomunicaciones; cables aéreos, submarinos y radiocomunicación."

10 Dictamen 1387/2009, de 17 de septiembre, pág. 23, continúa diciendo: "El otorgamiento de concesiones para la gestión indirecta del servicio, por su estrecha conexión con los medios de comunicación social solicitantes de concesiones y que se sirven como instrumento de las emisoras de difusión para ejercer los derechos fundamentales que el artículo 20. 1 de la Constitución consagra, es una medida que, por su finalidad, encuentra natural acomodo en el Título del artículo 149.1.27 de la Constitución. (...) En cambio, aspectos claramente atinentes a la regulación de los extremos técnicos del soporte o instrumento a través del cual la radio y la televisión aquí se sirven (...) quedan dentro de la materia "radiocomunicación" y, por tanto, de la competencia estatal ex artículo 149.1.21 de la Constitución. (...). Ciertamente (...) cabría admitir (...) la existencia de previsiones que escapan propiamente del ámbito de los medios de comunicación social para entrar en el terreno de las comunicaciones electrónicas, las cuales se sitúan en el ámbito de las telecomunicaciones. En cuanto a dichas precisiones (...) sería más ajustado al orden constitucional de distribución de competencias darles fundamento en la materia de telecomunicaciones prevista en el artículo 149.1.21․" 
mación (art. 20.1 d) ${ }^{11}$. De ser así, la materia entraría dentro de las reservadas $^{12}$ constitucionalmente a la ley orgánica.

Aunque el Consejo de Estado plantea esta duda en el Dictamen, lo cierto es que descarta casi desde el principio que el Anteproyecto deba seguir los cauces de una ley orgánica. Así, considera que "la expresión «desarrollo" de los derechos fundamentales, que utiliza el articulo 81 para determinar la materia reservada a ley orgánica, no puede llevar a su ámbito cualquier materia que tenga una conexión, más o menos remota, con un derecho fundamental (...), sino solo aquellas leyes que contengan una regulación directa de aspectos esenciales del derecho." ${ }^{13}$

El Consejo de Estado, por tanto, considera que la ley proyectada tiene por fin regular ciertos elementos de los servicios de la comunicación audiovisual, pero no elementos esenciales del derecho a la información, por lo que considera que debe adoptar la forma de ley ordinaria ${ }^{14}$.

\section{OBJETIVOS}

Los objetivos de la nueva ley son, como ya hemos apuntado mas arriba: 1) La transposición de la Directiva 2007/65/CE, de 11 de diciembre, al Derecho interno español; 2) Dotar al sector de una normativa adaptada al cambio técnico y que prepare el mercado para nuevos avances; 3) Compilar la normativa aún vigente tratando de actualizar los aspectos que hayan sufrido algún cambio y de eliminar las posibles lagunas jurídicas que puedan existir. Estos objetivos, que analizaremos de uno en uno, muestran, en palabras del Consejo de Estado "la ambición de la norma prevista y su propósito de convertirse en norma cabecera del sector de la comunicación audiovisual en España" ${ }^{15}$.

\section{II.1. TRAnSPosición DE LA Directiva 2007/65/CE}

Las nuevas tecnologías, o mejor dicho, los grandes cambios que han propiciado, son la base de las novedades introducidas por esta nueva norma eu-

11 STC 127/1994, Fundamento jurídico 4.B): «En nuestros días, la libertad de información es, casi sin excepción, un derecho a servirse de determinados medios, de manera que, de algún modo, la posibilidad de crear medios de comunicación social conecta y se integra con estos derechos fundamentales".

12 Artículo 81 CE.

13 Véase pág. 24 del Dictamen 1387/2009, de 17 de septiembre.

14 Dictamen 1387/2009, de 17 de septiembre, pág. 25: «La materia objeto de la ley proyectada no entra propiamente en el ámbito reservado a la ley orgánica, pues su finalidad es regular aspectos relativos a los servicios de comunicación audiovisual en tanto que instrumentos de comunicación pero no la determinación de elementos "esenciales" para el ejercicio del derecho fundamental citado".

15 Dictamen 1387/2009, de 17 de septiembre, pág. 25. 
ropea que viene a modificar la conocida como Directiva Televisión sin Fronteras de 1989. El Consejo de Estado se hace eco de esta realidad y expone que ulas modificaciones sustantivas introducidas por la Directiva 2007/65/CE se deben al impacto que sobre la originaria regulación comunitaria han introducido las nuevas tecnologías y que hacen necesaria una adaptación del marco regulador que refleje los efectos de los cambios estructurales, la difusión de las tecnologías de la información y de las comunicaciones, la evolución de los modelos de negocio (...). Su propósito es garantizar unas condiciones óptimas de competitividad y seguridad jurídica para las tecnologías de la información y los servicios e industrias de medios de comunicación en Europa, así como para el respeto de la diversidad cultural y lingüística ${ }^{16}$.

El Consejo de Estado considera que las aportaciones más novedosas son: la ampliación del ámbito de regulación de todos los medios de servicios audiovisuales, la modernización y simplificación del marco regulador de los servicios lineales, la flexibilización de las normas que regulan la publicidad y el establecimiento de unas bases claras para el emplazamiento de productos, el fomento del pluralismo en los medios de comunicación, así como de la diversidad cultural, y el reforzamiento en el medio audiovisual de la protección de los menores ${ }^{17} \mathrm{y}$ de los derechos de las personas con discapacidad ${ }^{18}$.

El Consejo de Estado recuerda que la norma comunitaria tiene carácter mínimo, es decir, que los Estados deben incluir en sus legislaciones internas, como mínimo, lo que recoge la Directiva, pero pueden hacer más rígidas las obligaciones si lo creen conveniente ${ }^{19}$, cosa que ha hecho España en diversos asuntos ${ }^{20}$. "La obligación ineludible es, por tanto, incorporar al ordena-

16 Dictamen 1387/2009, de 17 de septiembre, pág. 26.

17 Dictamen 1387/2009, de 17 de septiembre, pág. 36: «El considerando 67 indica que los objetivos de dicha Directiva son la creación de un espacio sin fronteras interiores para los servicios de comunicación audiovisual al mismo tiempo que vela por un alto nivel de protección de los objetivos de interés general, en particular le protección de los menores y de la dignidad humana, así como la promoción de los derechos de las personas con discapacidad. Uno de los principios cardinales de la regulación es el relativo a la diversidad cultural, haciendo suya el anteproyecto la denominada "excepción cultural".

18 El Consejo de Estado considera que la ley propuesta podría ser "más amplia en cuanto a la exigencia de accesibilidad, (...) además del lenguaje de signos y la descripción acústica, mencionando el subtitulado y los menús de pantalla fácilmente comprensibles». Dictamen 1387/2009, de 17 de septiembre, pág. 40.

19 Dictamen 1387/2009, de 17 de septiembre, pág. 26: «Hay que observar que la norma comunitaria tiene el carácter mínimo y, por tanto, los Estados son libres de elevar el nivel de las obligaciones si lo consideran conveniente para el interés general, exigiendo el cumplimiento de normas más estrictas o detalladas". De hecho, esta posibilidad queda recogida en la propia Directiva, en su artículo 3, donde dice: “Los Estados miembros tendrán la facultad de exigir a los prestadores del servicio de comunicación bajo su jurisdicción el cumplimiento de normas más estrictas o detalladas en los ámbitos regulados por la presente Directiva siempre y cuando estas normas sean conformes a la legislación comunitaria”.

20 Concretamente en lo referente a la prohibición de las comunicaciones comerciales relativas a bebidas alcohólicas (artículo 17.3.c) del Anteproyecto) y en la financiación de los prestadores del servicio público de comunicación audiovisual (artículo 42 del Anteproyecto). 
miento español la Directiva con su contenido íntegro y que se recojan con la mayor fidelidad posible sus preceptos ${ }^{21}$, si bien existe un amplio margen respecto a la forma en que se haga. La norma general, por lo tanto, es la libertad aunque se recomienda, por un lado, que la transposición no se entienda como una mera trascripción o como una copia literal; y por otro, que se ponga especial esmero en elegir opciones que no ocasionen conflictos interpretativos.

\section{II.2. AdAPTACiÓN DE LA LEY ESPAÑOLA A LA EVOLUCiÓN TECNOLÓGICA Y PREPARACIÓN DEL MERCADO AUDIOVISUAL PARA NUEVOS DESARROLLOS}

Con las nuevas tecnologías se ha hecho especialmente patente la idea de que el Derecho va por detrás de la realidad, pero en este caso como pone de manifiesto el Consejo de Estado, esta realidad ha ido acompañada de gran cantidad de disposiciones que además de ser dispares se han ido dictando de manera fragmentaria y urgente, lo que supone un gran peligro para la seguridad jurídica ${ }^{22}$. El cambio más significativo y que ha dado la vuelta al mercado de lo audiovisual ha sido el paso de la tecnología analógica a la tecnología digital. "Si tradicionalmente éste ha estado condicionado por la escasez del espectro radioeléctrico y consiguientemente por posibilidades restringidas en la oferta de servicios, la tecnología digital invierte tales premisas y plantea la necesidad de cambios ineludibles en los modelos de negocio". ${ }^{23}$.

En este punto, el Consejo de Estado hace referencia al concepto de "neutralidad tecnológica" ${ }^{24}$ como principio del que parten tanto la Directiva comunitaria como el Anteproyecto de ley que nos ocupa y como principio "que ha de inspirar la actuación de los poderes públicos en el ámbito audiovisual". Pero ¿qué debemos entender por neutralidad tecnológica? El Consejo de Estado no hace más referencia a ello, pero podemos decir que "supone la necesidad de ofrecer a los operadores, prestadores de servicios, adjudicatarios en concursos públicos, etc., la posibilidad de ofrecer los servicios a través de las tecnologías o infraestructuras que consideren más convenientes, no impidiendo la introducción y desarrollo de las nuevas tecnologías en el ámbito del libre mercado. (...) La lógica del principio de neutralidad tecnológica es aplastante: si un determinado servicio comienza a desarrollarse con una con-

21 Dictamen 1387/2009, de 17 de septiembre, pág. 27.

22 Esta cuestión enlaza directamente con el objetivo que nos ocupa y con el siguiente, puesto que por un lado muestra la necesidad de crear una norma que se ajuste a los cambios que se han producido y, por otro, indica que la gran cantidad de normas que se han ido creando deben ser compiladas y reunidas para dar una mayor seguridad jurídica al sector.

23 Dictamen 1387/2009, de 17 de septiembre, pág. 27, continúa diciendo: «Asimismo ha de tenerse en cuenta el fenómeno de convergencia entre los servicios de medios audiovisuales y los servicios de la sociedad de la información y del comercio electrónico y de las telecomunicaciones".

24 Principio recogido en el artículo 3 de la Ley General de Telecomunicaciones. 
creta tecnología disponible, la introducción de nuevas tecnologías, distintas de las existentes en el momento inicial, no puede ser impedida. Esto es así muy especialmente en supuestos como el que nos ocupa, donde el desarrollo e introducción de un determinado servicio se extiende necesariamente durante un período temporal relativamente largo" ${ }^{25}$

\section{II.3. COMPILACIÓN, ACTUALIZACIÓN Y NUEVA REGULACIÓN}

Uno de los objetivos de la ley proyectada, como ya hemos apuntado, es la de reunir todas las normas relativas al sector audiovisual que siguen estando vigentes pero que actualmente se encuentran dispersas, lo que se traduce en la existencia de una clara situación de inseguridad jurídica. El Consejo de Estado, tras hacer una serie de observaciones ${ }^{26}$ y recomendaciones, concluye que "procede en todo caso buscar un adecuado equilibrio que permita conjugar, de un lado, la introducción del máximo número de aspectos relevantes del sector audiovisual en la nueva ley junto con la suficiencia en su regulación y, de otro, las lógicas limitaciones de un texto normativo que tiene el carácter de básico en buena parte (...) y que se perfila con una vocación (...) que, en último término, podrían repercutir en la propia estabilidad de la norman.

\section{NOVEDADES}

La ley proyectada aporta diversas novedades respecto de la normativa existente sobre comunicación audiovisual. El Consejo de Estado destaca, de todas ellas, dos aspectos que considera especialmente novedosos. Por un lado, el hecho de que los servicios de comunicación audiovisual radiofónicos, televisivos, conexos e interactivos sean declarados de interés general, y por otro, la creación y regulación del Consejo Estatal de Medios Audiovisuales (CEMA).

25 Sentencia de la Audiencia Nacional de 19 de julio de 2005 (Recurso n 410/2002).

26 Dictamen 1387/2009, de 17 de septiembre, pág. 28 recoge alguna de ellas. Destaca, por ejemplo, que se observa un afán de regulación global de los medios de comunicación social audiovisuales por parte del Gobierno, dado que en el Anteproyecto se aborda una regulación más amplia que la que es objeto de la citada Directiva. A pesar de ello, observa que "el propósito compilador no llega a sus últimas consecuencias" y, además, algunos aspectos han sido desarrollados muy escasamente.

27 Dictamen 1387/2009, de 17 de septiembre, pág. 29. 


\section{III.1. LA DECLARACIÓN DE LOS SERVICIOS DE COMUNICACIÓN AUDIOVISUAL RADIOFÓNICOS, TELEVISIVOS, CONEXOS E INTERACTIVOS COMO SERVICIOS DE INTERÉS GENERAL ${ }^{28}$}

Esta aportación de la nueva ley se configura como una gran novedad dado que supone, según explica el Consejo de Estado, un cambio de filosofía respecto de la situación actual ${ }^{29}$. Esta novedad se considera positiva, pero se recuerda que el ser declarado de interés general comporta una serie de obligaciones $^{30}$, además de que conlleva la necesaria intervención de la Autoridad competente, lo que impediría hablar de una liberalización incondicionada del sector. Dentro de esta novedad, la manifestación más significativa del cambio — según el Consejo de Estado-, "aparece representada por el tránsito desde el régimen actual de autorizaciones y concesiones para la gestión indirecta del servicio público de titularidad estatal hacia un régimen de comunicaciones previas y de licencias otorgadas mediante concurso" ${ }^{31}$.

Finalmente, conviene tener en cuenta que el servicio público de comunicación audiovisual como servicio esencial, sólo queda en manos del Estado, las Comunidades Autónomas y las Entidades locales, como se desprende del artículo 39 de la nueva Ley ${ }^{32}$.

28 Artículo 21 Anteproyecto Ley general Audiovisual, sobre Libertad de empresa: "1. Los servicios de comunicación audiovisual radiofónicos, televisivos o conexos e interactivos son servicios de interés general que se prestan en el ejercicio del derecho a la libertad de empresa, en régimen de libre competencia y dentro de un mercado transparente y plural. 2. La prestación del servicio requiere comunicación ante la autoridad audiovisual competente y previa al inicio de la actividad. 3. Cuando dichos servicios se presten mediante ondas hertzianas terrestres necesitarán licencia previa otorgada, mediante concurso por la autoridad audiovisual competente. En el ámbito de cobertura estatal, la competencia para el otorgamiento de las licencias, incluidas las de radiodifusión digital terrenal y onda media corresponde al Gobierno. Para la prestación del servicio de comunicación televisiva las licencias de ámbito local podrán corresponder a uno o varios municipios limítrofes y, en su caso, a un ámbito insular completo. El otorgamiento de una licencia de televisión de ámbito local no faculta para la emisión en cadena con otras entidades autorizadas, durante más del 25\% del tiempo total semanal, aunque sea en horario diferente. En ningún caso este porcentaje puede concentrarse en el horario de 21 a 24 horas. Se reconoce el derecho de los prestadores del servicio de comunicación radiofónica a emitir su programación en cadena, cuando un mismo prestador haya obtenido licencias en diversos ámbitos territoriales o haya alcanzado acuerdos con otros titulares de licencias en una o varias Comunidades Autónomas".

29 Dictamen 1387/2009, de 17 de septiembre, pág. 29: "Sin infravalorar el alcance de esta novedad, hay que apuntar que, en realidad, solo afectará a los servicios audiovisuales que se presten por ondas hertzianas terrestres puesto que la liberación ha llegado ya a los restantes".

30 Vid supra nota 19.

31 Dictamen 1387/2009, de 17 de septiembre, pág. 29.

32 Artículo 39 Anteproyecto Ley general Audiovisual, sobre Servicio público audiovisual: "1. El servicio público de comunicación audiovisual es un servicio esencial para la comunidad que tiene como función principal difundir contenidos que fomenten los principios y valores constitucionales, contribuir a la formación de una opinión pública plural, dar a conocer la diversidad cultural y lingüística de España, y difundir el conocimiento y las artes. Los prestadores del servicio público de comunicación audiovisual atenderán a aquellos ciudadanos y grupos sociales que no son destinatarios de la programación mayoritaria. 2. El Estado, las Comunidades Autónomas y las Entidades Locales podrán acordar la prestación del servicio público de comunicación audio- 


\section{III.2. La CREACión y Regulación del Consejo estatal de Medios Audiovisuales (CEMA)}

La creación y regulación de un órgano regulador y supervisor independiente para el sector audiovisual, como es el Consejo Estatal de Medios Audiovisuales, supone una novedad absoluta dentro del ordenamiento español y, según el Consejo de Estado, "responde a una demanda reiterada de la sociedad y de los agentes del mercado audiovisual ${ }^{33}$. La creación de un órgano de esta índole se presenta como una asignatura pendiente, en el sentido de que su creación "pondrá fin a una significativa divergencia de España con respecto a los Estados de nuestro entorno "34.

El CEMA que se propone en el Anteproyecto sería competente en relación con el mercado audiovisual estatal, sin entrar en las competencias autonómicas que, por otro lado debe respetar. No hay que olvidar, además, que algunas Comunidades Autónomas ya han ejercido las competencias que les correspondían dentro de su ámbito y han creado sus propios Consejos Audiovisuales. Así por ejemplo, ya se han creado: El Consejo Audiovisual de Cataluña (2000), el Consejo Audiovisual de Navarra (2001), el Consejo Audiovisual de Andalucía (2004) o el Consejo Audiovisual de la Comunidad de Madrid (2005).

Para el Consejo de Estado es notorio y digno de destacar el nivel de independencia con que se configura el CEMA ${ }^{35}$, en el sentido de que se crea fuera del orden jerárquico de la Administración General del Estado y totalmente desvinculado de los otros órganos ya existentes. Para conseguir este fin, la ley proyectada incluye un adecuado sistema de nombramiento ${ }^{36} \mathrm{y}$ cese $^{37}$ de los miembros, de modo que parece que la independencia queda ga-

visual con objeto de emitir en abierto canales generalistas o temáticos. 3. La emisión del servicio público de comunicación audiovisual por ondas hertzianas terrestres de una Comunidad o Ciudad Autónoma en otra distinta podrá ser efectuada siempre que así lo acuerden mediante convenio, exista reciprocidad y reciba autorización estatal previa."

33 El Senado solicitó su creación en 1995 y España votó a favor de la Recomendación aprobada en 2000 por el Consejo de Europa, en la que se instaba a los Estados miembros a crear órganos de este tipo.

34 Dictamen 1387/2009, de 17 de septiembre, pág. 30.

35 Artículo 49 Anteproyecto Ley general Audiovisual, sobre el estatuto personal: «3. Los miembros del Comité de Dirección ejercerán su cargo con absoluta independencia del Gobierno y de los operadores del sector. A estos efectos estarán sujetos a la Ley 5/2006, de 10 de abril, de regulación de los conflictos de intereses de los miembros del Gobierno y de los Altos Cargos de la Administración General del Estado."

36 Artículo 48 Anteproyecto Ley general Audiovisual, sobre los órganos directivos: «1. El Consejo Estatal de Medios Audiovisuales estará regido por un Comité de Dirección, al que corresponderá el ejercicio de las funciones establecidas en el artículo 50. El Comité de Dirección estará compuesto por la Presidencia, la Vicepresidencia y siete consejerías cuyos titulares serán nombrados por el Gobierno mediante Real Decreto, a propuesta del Congreso de los Diputados por mayoría de tres quintos entre personas de reconocida competencia en materias relacionadas con el sector audiovisual."

37 Artículo 49 Anteproyecto Ley General Audiovisual, sobre el estatuto personal: “2. Los miembros del Consejo Estatal Audiovisual cesarán en su cargo por las causas siguientes: 
rantizada efectivamente ${ }^{38}$. Esto no significa, como apunta el Consejo de Estado, que el CEMA no deba estar adscrito a un órgano de la Administración General del Estado, dado que tanto ésta como el Gobierno tendrán que ejercer ciertas funciones acerca de él, aunque eso sí, respetando su ámbito de autonomía.

En relación con la composición del CEMA, el Consejo de Estado hace dos recomendaciones. La primera es que se debería tener en cuenta al Senado para la función de proponer Consejeros y no sólo al Congreso. La segunda se refiere a lo estipulado en el artículo 48 de la ley, cuando dice que los consejeros propuestos serán personas de reconocida competencia en materias relacionadas con el sector audiovisual. En este punto, el Consejo de Estado considera que "aunque dicha cualificación se entienda que debe ser preferente, no parece necesario un límite legal previo que inhiba la designación de candidatos que procedan de ámbitos también ligados a otros contenidos relevantes de la futura institución (como son, por ejemplo, los provenientes de los sectores económico y jurídico). La independencia del CEMA se asentará, sobre todo, en la calidad y capacidad de sus miembros y ello aboga por propugnar que su composición se abra a un más amplio elenco de candidatos „39.

\section{OBSERVACIONES}

A lo largo del Dictamen, el Consejo de Estado analiza las diferentes partes de que consta el Anteproyecto presentado alabando en ocasiones el trabajo realizado o dando toques de atención sobre los puntos que a su criterio deberían ser modificados. No nos parece necesario incluir en este trabajo un listado exhaustivo de estas observaciones y recomendaciones, por lo que tan sólo recogeremos aquellas que nos parezcan mas significativas por la materia sobre la que versen o porque el Consejo les haya dedicado una especial atención.

a) Una de las recomendaciones más recurrentes es que sería conveniente mantener en la ley la misma estructura que en la Directiva, así como utilizar los mismos nombres y definiciones al referirse a la misma cosa, pues el Con-

a) Expiración del término de su mandato.

b) Renuncia aceptada por el Congreso de los Diputados.

c) Separación acordada por el Consejo de Ministros por incapacidad permanente para el ejercicio de su función, incompatibilidad sobrevenida o condena por delito doloso.

d) Separación acordada por el Consejo de Ministros debido al incumplimiento grave de sus obligaciones, cuando así sea apreciado por una mayoría de tres quintos del Congreso de los Diputados."

38 Dictamen 1387/2009, de 17 de septiembre, pág. 55: "De otra manera, una mera declaración de independencia resultaría ilusoria e insuficiente si no fuera acompañada de un sistema de nombramiento y cese de los miembros del órgano que la garantice efectivamente, siendo éste un aspecto que se ha previsto adecuadamente en el anteproyecto".

39 Dictamen 1387/2009, de 17 de septiembre, pág. 57. 
sejo considera que "la asimetría en las categorías usadas por la Directiva y el anteproyecto (...), aunque por sí misma no sea determinante de un incumplimiento de la Directiva, ya que dicha norma de Derecho Comunitario es finalista y deja libertad a cada estado miembro en cuanto a los medios para lograr sus objetivos, puede dar lugar en algunos casos a confusión y, en último término, convertirse en germen de potenciales conflictos interpretativos ${ }^{40}$.

b) El Consejo de Estado considera, como ya se ha apuntado, que el texto satisface en general las obligaciones que le impone el Derecho comunitario, pero considera que en el apartado relativo a los derechos del público "la regulación adolece de un planteamiento impropio al configurar como derechos del público lo que en la directiva aparecen enunciados como obligaciones de los prestadores de servicio. Si bien puede poner énfasis en los derechos, no cabe desdibujar la naturaleza de obligaciones y deberes que se extrae de la Directiva, además de que, desde un punto de vista conceptual, no toda obligación lleva aparejado un derecho subjetivo de correlaton. ${ }^{41}$

c) Al abordar el capítulo destinado a los derechos del público, el Consejo de Estado considera que sería necesario que se incorporara una legislación específica del derecho de réplica, no siendo suficiente, a su parecer, para dar satisfacción real a la Directiva ${ }^{42}$, la referencia genérica que se hace al derecho de rectificación y la ley que lo regula (L.O.2/1984, de 26 de marzo, Reguladora del derecho de rectificación).

d) En cuanto a los derechos del menor y su protección, el Consejo de Estado recoge la queja formulada por la Asociación de Usuarios de la Comunicación relativa a que el Anteproyecto debería establecer medidas un poco más exigentes con la protección del menor. Se quejan de que incluso han desaparecido algunas de las normas contenidas en la legislación vigente. Dicen que "no hay referencia en el anteproyecto a la obligación de clasificación de películas por edades o a la prohibición del abuso de la confianza en "profesionales de programas infantiles o, eventualmente, en personajes de ficción ${ }^{43}$.

e) El artículo 11 del anteproyecto se refiere a la autorregulación del prestador del servicio de comunicación audiovisual ${ }^{44}$. El Consejo de Estado,

40 Dictamen 1387/2009, de 17 de septiembre, pág. 34.

41 Dictamen 1387/2009, de 17 de septiembre, pág. 37.

42 Dictamen 1387/2009, de 17 de septiembre, pág. 37: “Cualquier persona física o jurídica, independientemente de su nacionalidad, cuyos legítimos derechos, en particular por lo que atañe a su honor y su reputación, hayan sido lesionados como consecuencia de una alegación incorrecta hecha en un programa televisivo deberá poder disponer de un derecho de réplica o de medidas equivalentes".

43 Dictamen 1387/2009, de 17 de septiembre, pág. 39.

44 Artículo 11 Anteproyecto Ley General Audiovisual: «1. Los prestadores del servicio de comunicación audiovisual tienen el derecho a aprobar códigos en los que se regulen los contenidos de la comunicación audiovisual y las reglas de diligencia profesional para su elaboración. 2. Cuando un prestador apruebe un código por sí solo, en conjunto con otros prestadores, o se adhiera a uno ya existente, lo comunicará a la autoridad audiovisual competente. Esta autoridad verificará la conformidad con la normativa vigente y de no haber contradicciones dispondrá su publicación. 3. Las autoridades audiovisuales deben velar por el cumplimiento de los códigos". 
después de determinar que el texto de la Directiva es, respecto de este tema, menos amplio pero más preciso, establece que "si bien la autorregulación puede ser un método complementario para aplicar ciertas disposiciones de la Directiva, en forma alguna puede sustituir a las obligaciones del poder legislativo nacional ${ }^{45}$.

f) La publicidad, o mejor dicho, las comunicaciones comerciales son uno de los asuntos que más ha dado que hablar entre los profesionales del sector, una vez conocido el texto del anteproyecto. El Consejo de Estado también se refiere a ella, si bien es cierto que casi todas sus aportaciones se refieren a solventar problemas de concepto. Por si cabía alguna dudad, explica que los cambios introducidos por la Directiva 2007/65/CE «no deben incrementar la cantidad de tiempo por hora que es admisible la publicidad, (...) pero debe ofrecer flexibilidad con respecto a su inserción cuando ello no perjudique indebidamente la integridad de los programas ${ }^{46}$. Parece ser que con esto lo que se pretende es salvaguardar las formas de presentar la publicidad en la televisión europea, esto es, ente programas y no dentro de ellos como hasta ahora ocurre en nuestro país.

\section{VALORACIÓN GENERAL}

La valoración general que el Consejo de Estado hace del Anteproyecto de la Ley General Audiovisual es favorable ${ }^{47}$, a pesar de las observaciones realizadas y que han quedado apuntadas en este trabajo aunque sea de forma sucinta y resumida. El Consejo recuerda que éste no es el primer intento de aprobar una norma general del sector audiovisual (en 2005 ya se tramitó otro Anteproyecto de Ley General Audiovisual ${ }^{48}$ ) y recuerda que el éxito de la misma puede depender del grado de consenso - entre todas las partes interesadas - al que se consiga llegar, puesto que consenso es lo que ha faltado hasta el momento y de que lo haya o no dependerá, en gran medida, la estabilidad de la nueva ley.

45 Dictamen 1387/2009, de 17 de septiembre, pág. 42.

46 Dictamen 1387/2009, de 17 de septiembre, pág. 43.

47 Dictamen 1387/2009, de 17 de septiembre, pág. 30: "En términos generales puede decirse que el texto consultado cumple de modo razonable sus objetivos, que es sucinto pero suficientemente completo ante la enorme amplitud de sus propósitos y que contiene la regulación esencial básica mínima para una ordenación y coordinación del sector audiovisual en España. Responde adecuadamente a los objetivos de la Directiva de servicios de comunicación audiovisual, observa el marco constitucional de distribución de competencias entre el Estado y las Comunidades Autónomas (y, en su caso, las Corporaciones locales), es proporcionado y respeta en su regulación el principio de intervención mínima de los poderes públicos".

48 El Consejo de Estado se pronunció sobre él en el Dictamen 1.701/2005 y su valoración final también fue positiva. 
TITLE: Comments on the opinion of the Council of State relative to the preliminary design of the General Audio-visual Communication Act.

ABSTRACT: New technological developments in the audiovisual field has made necessary the drafting of new rules adapted to the big changes that are living inside the sector. It is a legislative necesary process that the professionals caom claming and should answer three fundamental questions. The first would be to provide the sector with legislation which, on the one hand, will be adapt to technical change which will mean the transition from analog media to digital media and, secondly, ensure legal certainty for companies and protect the ribgts of citizens; the second issue that requires a new law is the need to traspose Directive 2007/65/EC of 11 Decembre, to the internal Spanish Law and, last, is the convenience of compiling the whole regulation even in force trying to update the aspects that have suffered some change and to eliminate possible juridical lagoons that could exist. Facing this challenge, the Goverment has prepared a draft bill on which he has sought advice on the Council of State, which after a series of obervations that request the Goverment to take into account, has given his approval for de Preliminary pass to undergo to approval by the Council of Ministers.

RESUMEN: Los nuevos avances tecnológicos en el ámbito audiovisual han hecho necesaria la redacción de una nueva normativa adaptada a los grandes cambios que se están viviendo dentro del sector. Se trata de un proceso legislativo necesario que vienen reclamando los profesionales de lo audiovisual y que deberia dar respuesta a tres cuestiones fundamentales. La primera sería la de dotar al sector de una normativa que por un lado esté adaptada al cambio técnico que va a suponer el paso de los medios analógicos a los medios digitales y que, por otro, asegure la seguridad jurídica de las empresas y proteja los derechos de los ciudadanos; la segunda cuestión que hace necesaria una nueva ley es la necesidad de transponer la Directiva 2007/65/CE, de 11 de diciembre, al Derecho interno español y, la última, dirigida a asegurar una mayor seguridad jurídica en el campo audiovisual, es la conveniencia de compilar toda la normativa aún vigente tratando de actualizar los aspectos que hayan sufrido algún cambio y de eliminar las posibles lagunas jurídicas que puedan existir. Ante este reto, el Gobierno ha redactado un Anteproyecto de Ley sobre el que ha pedido asesoramiento al Consejo de Estado, el que tras una serie de observaciones que pide al Gobierno tome en consideración, ha dado su visto bueno para que el Anteproyecto pase a someterse a la aprobación del Consejo de Ministros.

KeY words: Audio-visual communication. Telecommunications. State Council of Audio-visual Means. New technologies. Lenders of service. Producer. Advertising. Commercial communication. Emplacement of product.

Palabras Clave: Comunicación audiovisual. Telecomunicaciones. Consejo Estatal de Medios Audiovisuales (CEMA). Nuevas tecnologias. Prestadores de servicio. Productor. Publicidad. Comunicación comercial. Emplazamiento de producto. 